\title{
Parental Knowledge, Attitudes, and Practices Towards Self-Medication for Their Children: a Cross-Sectional Study from Palestine
}

\author{
Sa'ed H. Zyoud ${ }^{1,2^{*}}$, Rawan M. Shtaya ${ }^{3}$, Dana Q. Hamadneh ${ }^{3}$, Shyma N. Sawalmeh ${ }^{3}$, Hiba A. Khadrah ${ }^{3}$, \\ Rasha R. Zedat ${ }^{3}$, Abdullah Othman ${ }^{4}$, Waleed M Sweileh ${ }^{5}$, Rahmat Awang ${ }^{6}$, Samah W Al-Jabi ${ }^{1}$
}

\begin{abstract}
Background: Self-therapy with various medications is a commonly practised form of children self-care among parents throughout the world, with the prevalence and pattern differing from country to country. Parental knowledge, attitudes, and practices (KAP) regarding self-medication of their children need to be taken into consideration because children are more sensitive to adverse consequences of medication. This study was designed to assess Palestinian parents' KAP towards self-medication for their children. Methods: A descriptive, cross-sectional study was conducted in Palestine from October 2016 to February 2017, using a face-to-face interview questionnaire format, which was adapted from previous studies in this field. Data was collected by convenient sampling. The parents answered a questionnaire covering socio-demographic and economic variables; medication information; knowledge, attitudes, and practices regarding self-medication; and the toxicity of medications used for self-therapy. Results: Among the 500 respondents interviewed, the total parents of $357(73.4 \%)$ accepted using medications as self-therapy for their children. The most common reason for using self-medication was previous experience $(54.6 \%)$. The medications most often used in such self-therapy are antipyretics (95\%), followed by skin creams (46\%) and anti-cough and anti-influenza medication $(44.2 \%)$. Parental knowledge about toxicity was found to be inadequate. For example, around $70 \%$ of parents believe that paracetamol and multivitamin are not fatal in cases of overdose. Conclusions: Self-medication of children is common among parents in Palestine. There has been a high tendency for parents to self-medicate their children, in particular with antipyretics. Moreover, antibiotics have been used without prescriptions by a large proportion of parents. As such, specific guidelines for appropriate self-therapy should be established. We must encourage pharmacists to educate parents on how to self-medicate medicine in proper doses and at the correct time, as well when the dose reaches a toxic level.
\end{abstract}

Keywords: children; Palestine; parents; self-medications; self-therapy

Division of Clinical and Community Pharmacy, College of Medicine and Health Sciences,

An-Najah National University, Nablus 44839, Palestine

${ }^{2}$ Clinical Research Centre, An-Najah National University Hospital, Nablus, 44839, Palestine

${ }^{3}$ Pharmacy program, Department of Pharmacy, College of Medicine and Health Sciences,

An-Najah National University, Nablus 44839, Palestine

${ }^{4}$ Department of Medicine, College of Medicine and Health Sciences,

An-Najah National University, Nablus 44839, Palestine

${ }^{5}$ Department of Pharmacology and Toxicology, College of Medicine and Health Sciences,

An-Najah National University, Nablus 44839, Palestine

${ }^{6}$ WHO Collaborating Centre for Drug Information, National Poison Centre,

Universiti Sains Malaysia (USM), 11800 Penang, Malaysia

\section{Corressponding Author}

Sa'ed H. Zyoud, Poison Control and Drug Information Center (PCDIC), College of Medicine and Health Sciences,

An-Najah National University, Nablus 44839, Palestine.

E-mails: saedzyoud@yahoo.com, saedzyoud@najah.edu

\begin{tabular}{ll} 
& \multicolumn{1}{c}{ Contents } \\
1 & Introduction \\
2 & Methods \\
2.1 & Study design \\
2.2 & Study area and population of study \\
2.3 & Sample size \\
2.4 & Data collection instrument \\
2.5 & Statistical analysis \\
2.6 & Ethical approval \\
3 & Results \\
4 & Demographic data \\
$\mathbf{5}$ & Discussion \\
$\mathbf{6}$ & Conclusions \\
$\mathbf{7}$ & References
\end{tabular}

\section{Introduction}

The use of medication without advice from a health worker regarding the suitable medication for the desired aliments is defined as self-medication $[1,2]$. Every day around the world, at least one consumer takes a self-medicated drug because it is easier, less expensive, less time consuming, and more cost-efficient. However, self-medication in children is associated with risks such as misdiagnosis, prolonged duration of use, and inappropriate dosage regimen [2, $3]$, highlighting the need for greater awareness and knowledge among consumers. In some cases, the misuse of self-medication can lead to serious problems and drug interactions. For example, life threatening Reye syndrome can occur if Aspirin is used for children younger than 12 with viral infections [4]. Children make up a large part of the population in developing countries, and minor diseases, such as fever, cough, cold and colic, occur most frequently during childhood [5]. A large population of parents treat their sick children with self-medication as a first step before asking the doctor [6]. Parents may base their decisions when dealing with ailments on information about drugs 
from family, media, community, past experience and other sources [7].

Previous studies that focused on self-medication of children indicated that $70 \%$ of illnesses among children were treated with self-medication in the U.S.A. [8]. However, in 2008, a survey conducted with a group of Japanese parents found that $60.5 \%$ didn't know the meaning of self-medication [9]. However, the use of self-medication for children was often inaccurate, with $71 \%$ of parents in a U.S. study failing to use self-medication in the appropriate way, and only $10.91 \%$ of parents saying that they read labels and drug information [10]. Parental attitudes about self-therapy for their children have been studied in an earlier study, which showed that parents with a good attitude towards self-medication are more ready to treat their own children [11, 12]. Many studies have reported on the percentage of parents that use self-medication on their children, for example, $53.8 \%$ of Saudi Arabia parent's and $95.7 \%$ of Sudanese parent's encourage self-medication $[13,14]$.

A similar study in India showed that $58.91 \%$ of mothers medicated their children with non-prescribed medication for common health problems [15]. Additionally, another study reported analgesic, anti-pyretic, and anti-cough medicines as the medications most commonly used in treat these children [16]. According to another study, the main reported reason for using self-medication on their children was that consultations with doctors were more expensive and time-consuming [17].

The issue of self-medication of children differs from other cases of self-medication because the parents are responsible for treating their children, rather than the children themselves. The relation between parents' attitudes and the medicines used to treat their children's common ailments, such as flu, cough, fever, diarrhoea, pain, and colic, has been a major focus of many earlier studies [18-22]. In general, the effect of parents' knowledge, perception, and practices of self-medication of their children on medicine use in children isn't well known [17, 19]. Therefore, the main aim of this study was to detect the current knowledge, attitudes, and practices (KAP) of parents towards selfmedication for their children. This could supply baseline data for developing plans to increase people's awareness in the health field. The results of this study are a first trial to identify parents' KAP towards self-medication for their children in Palestine, which is essential to any efforts to upgrade the quality of health services in Palestine.

\section{Methods}

\subsection{Study design}

A descriptive, cross-sectional study was conducted in Palestine from October 2016 to February 2017.

\subsection{Study area and population of the study}

The population of the study included any parents who were more than 18 year old, and who had at least one child younger than 18 , without chronic illness, such as cardiovascular diseases, asthma, and diabetes mellitus. The study was carried out at healthcare centres for children, government clinic and private clinic in Nablus district.

\subsection{Sample size}

An online Raosoft sample size calculator (http://www. raosoft.com/samplesize.html) was applied to determine the sample size, which resulted in sample size of 500. This is after assuming confidence level of $95 \%$, a margin of error of $5 \%$, and a response distribution of $50 \%$, and adding a non-response rate of $20 \%$ to increase the accuracy. The inclusion criteria were: 1) Parents with at least one child aged younger than 18,2 ) who provided verbal agreement for participation, and 3) who do not work in the health field (doctors, pharmacist, and nurses).

\subsection{Data collection instrument}

Parents were interviewed face-to-face, using a questionnaire created based on other previous similar studies [4, 13, 17 , 23-28] (see Additional File 1). We performed a literature review to develop a questionnaire that included appropriate measurements of parents' knowledge, attitudes, and experience of home medicine use. The questionnaire included 37 questions and was divided into seven sections. Each section generated responses in several forms, including closed-ended questions with multiple answers, "Yes", "No", and "Don't know", as well as open questions

First section: This section was composed of eleven items, with the focus on basic data about respondents (e.g. age, gender, place of residence, income, number of children, parental education level, job, and health status of children).

Second section: This section was designed to uncover the source of information about medication used by parents, and the reasons for engaging in self-medication.

Third section: This section consisted of six statements to assess parents' knowledge about self-medication. The respondents were requested to choose among three options provided, "yes", "no", and "don't know". The score for knowledge was measured by calculating the number of correct answers on three of these items, and the answers of "don't know" were added as incorrect answers (i.e., 1 point for correct, and 0 for incorrect).

Fourth section: this section contains questions to assess parents' attitude and beliefs regarding the efficacy and safety of self-therapy

Fifth section: This section consisted of questions to examine parents' behaviour regarding self-medication and the dosage form most preferred by parents.

Sixth section: This section consisted of questions to determine the medications used most frequently by parents on their children without consulting a doctor or pharmacist.

Seventh section: This section consisted of questions to evaluate parents' general knowledge regarding the safety and toxicity of the products used for self-medication. All 
questions in this section were selected from previous studies [28].

A research team, consisting of three experts in the area of self-therapy and clinical pharmacy, were asked to review the items' appearance, representativeness, relevance, and the appropriateness of its components, and they recognised the face and content validity of the study instrument. Some items were removed or modified accordingly. The first copy of the questionnaire was completed and revised by the investigators, and subsequently tested by means of a pilot study conducted on 30 parents. Following this, all unclear questions were modified. The Cronbach's alpha as a measure for internal consistency reliability of questionnaire was 0.77 for knowledge scale, 0.82 for attitude scale, and 0.65 for behaviour scale.

\subsection{Statistical analysis}

The data was coded, categorised, and entered in Statistical Package for the Social Sciences (SPSS), version 16.0. Descriptive statistics (e.g. frequency, percentage, mean, standard deviation, median, interquartile range) were used to illustrate the socio-demographic data. To calculate the score for knowledge, one point was given for each correct answer and zero for each incorrect answer, and the answers of "do not know" were added as incorrect answers. Furthermore, descriptive statistics of the respondents' knowledge, attitude, perception, and behaviour concerning self-medication use were reported. Nonparametric MannWhitney tests (for dichotomous variables with continuous data) and Kruskal-Wallis tests (for multicategory variables with continuous data) were used where appropriate. Results were considered statistically significant when $\mathrm{P}<0.05$.

\subsection{Ethical approval}

All aspects of the study protocol were approved by Institutional Review Boards (IRB) at An-Najah National University. Permission to interview parents was granted by the Palestinian Ministry of Health or a head of a private clinic. Data was collected from parents only upon obtaining verbal informed consent in line with the requirements of the IRB. Furthermore, the parents were notified that their answers would be kept totally confidential and would only be used for scientific research purposes. The time required to complete the questionnaire was only 5 minutes.

\section{Results}

\section{Demographic data}

A total of 510 questionnaires were distributed, and 500 questionnaires were completed and returned, giving a response rate of $98.03 \%$. Of these, 307 questionnaires were distributed in government healthcare centres, and 203 questionnaires were collected from a private paediatric clinic. Table 1 provides the summary statistics for the social demographic characteristics of the study population. Regarding the gender distribution of the sample, 91.4\% were females and $8.6 \%$ males, with an overall mean age of $31.4 \pm 7.8$.
Table 1. Socio-demographic characteristics of the study population $(\mathrm{n}=500)$

\begin{tabular}{|c|c|}
\hline Question & $\mathbf{N}(\%)$ or mean $\pm \mathrm{SD}$ \\
\hline \multicolumn{2}{|l|}{ Gender } \\
\hline Male & $43(8.6)$ \\
\hline Female & 457 (91.4) \\
\hline Age \pm SD (year) & $31.4 \pm 7.8$ \\
\hline \multicolumn{2}{|l|}{ Place of residence } \\
\hline City & $263(52.6)$ \\
\hline Village & $219(43.8)$ \\
\hline $\begin{array}{l}\text { Palestinian refugee } \\
\text { camp }\end{array}$ & $18(3.6)$ \\
\hline \multicolumn{2}{|l|}{ Education } \\
\hline Un-educated & $2(0.4)$ \\
\hline Primary-education & $36(7.2)$ \\
\hline Secondary-education & $149(29.8)$ \\
\hline University Education & $313(62.6)$ \\
\hline \multicolumn{2}{|l|}{ Father job } \\
\hline Employee & $491(98.2)$ \\
\hline Unemployed & $9(1.8)$ \\
\hline \multicolumn{2}{|l|}{ Mother job } \\
\hline Employee & $81(16.2)$ \\
\hline Unemployed & $419(83.8)$ \\
\hline \multicolumn{2}{|l|}{ Income level in month \# } \\
\hline Low (Less than 2000 NIS) & $122(24.4)$ \\
\hline Moderate (2000-5000 NIS) & $321(64.2)$ \\
\hline High (More than 5000 NIS) & $57(11.4)$ \\
\hline \multicolumn{2}{|l|}{ Health insurance type } \\
\hline Government & $312(62.4)$ \\
\hline Private & $60(12)$ \\
\hline None & $118(23.6)$ \\
\hline Both & $10(2)$ \\
\hline \multicolumn{2}{|l|}{ Child has a chronic medical problem } \\
\hline Yes & $40(8)$ \\
\hline No & $460(92)$ \\
\hline \multicolumn{2}{|l|}{ The type of chronic illness of the child } \\
\hline Hearing loss & $4(0.8)$ \\
\hline Cardiovascular disease & $6(1.2)$ \\
\hline Leukaemia & $2(0.4)$ \\
\hline Asthma & $6(1.2)$ \\
\hline Diabetes mellitus & $2(0.4)$ \\
\hline Overactive thyroid gland & $3(0.6)$ \\
\hline Epilepsy & $2(0.4)$ \\
\hline Other & $12(2.4)$ \\
\hline \multicolumn{2}{|l|}{ Place of data collection } \\
\hline Government & $300(60)$ \\
\hline Clinical & $200(40)$ \\
\hline
\end{tabular}

NIS, New Israeli shekel; \%, Percentage; SD, standard deviation \# 1 New Israeli Shekel equals 0.29 US Dollar

\section{Preferred types of therapy used by parents on their children}

When we asked parents about their preferences for using prescription drugs to treat their children, $91.8 \%$ of them said that they preferred to do so. Regarding over-thecounter drugs, only $27.2 \%$ of parents preferred to use them. About $41.2 \%$ of parents prefer use self-therapy in their life, and, in total, $35.8 \%$ prefer to use alternative and herbal medicine (Table 2).

\section{Reasons for parents engaging in self-therapy}

Three hundred and sixty-seven parents (73.4\%) gave their children at least one medicine without the advice of a doctor or pharmacists when their children felt sick. When we asked parents about the reasons for using self-therapy on their 
Table 2. Preferred type of therapy used by parents to their children

\begin{tabular}{|c|c|}
\hline Therapy type & N (\%) \\
\hline Prescriptive medications & $459(91.8)$ \\
Over-the-counter medications (OTC) & $136(27.2)$ \\
Self-therapy & $206(41.2)$ \\
Alternative and Herbal medicine & $179(35.8)$ \\
\hline
\end{tabular}

children, most of them $(54.6 \%)$ said they had sufficient

they were able to ascertain the disease from symptoms. The experience to treat their children, and $49.2 \%$ claimed that

other reasons given are presented in Table 3.

Table 3. Reasons for self-medication

\begin{tabular}{|l|c|}
\hline Reason for self-medication & $\mathbf{N}(\%)$ \\
\hline - The cost of going to the doctor is high & $106(21.2)$ \\
- Waiting so long in the clinic & $65(13)$ \\
- Parents can ascertain the child's disease from the symptoms & $246(49.2)$ \\
- The workers in the medical field are not qualified & $24(4.8)$ \\
- Having experience of treating children & $273(54.6)$ \\
- The nearest clinic is too far from the parent's place of residence & $37(7.4)$ \\
\hline
\end{tabular}

\section{Source of information about self-therapy}

Most parents (82.8\%) stated that the leaflet inside the drug was the main source of information about the medicine, followed by previous experience, which constituted $55.8 \%$, followed by other sources, such as the internet, members of the community, the radio, TV, and others, as detailed in Figure 1 .

\section{Parents' knowledge regarding self-therapy}

More than ninety percent of parents knew that completing the drug course is essential for full improvement. However, only $23 \%$ of parents knew that the number of active ingredients does not affect the activity of the medicine. More than two thirds (87\%) of parents were aware that the required concentration of the active ingredient in the drug

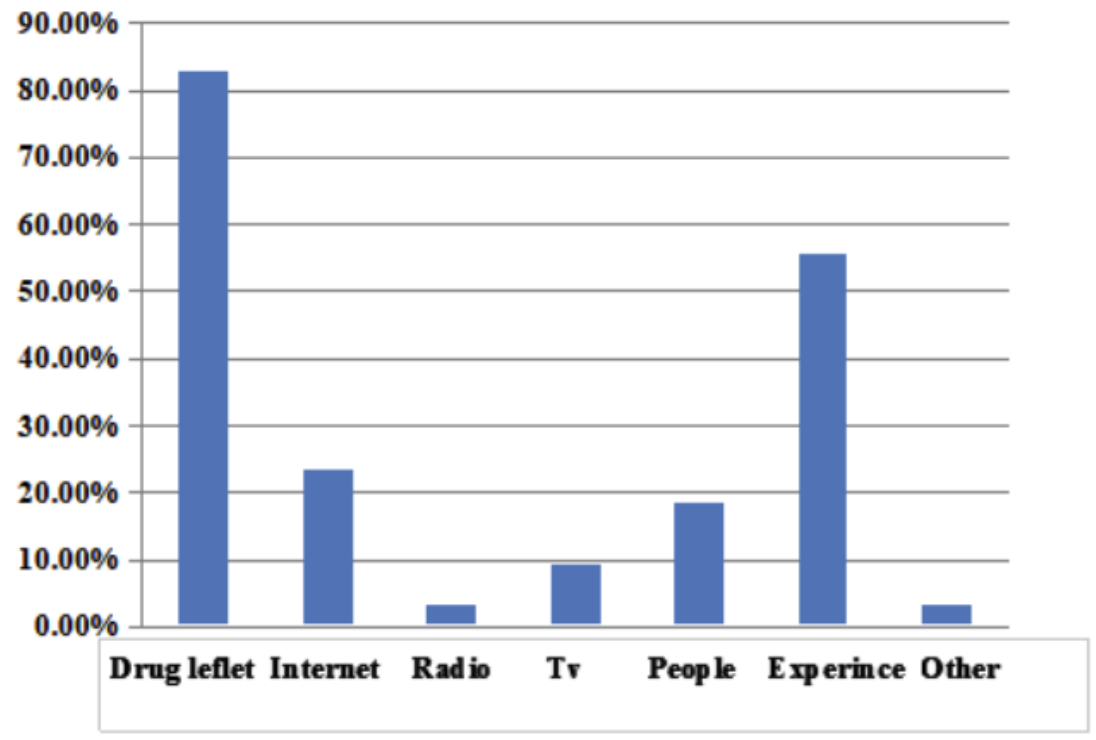

Figure 1. Sources of drug information in self-medication

depends on the child's age. Details are shown in Table 4. Knowledge scores ranged from 1 to 6 , with a mean score of $4.38 \pm 1.05$ and median score 4 with interquartile range between 4 and 5 . There were no significant differences found on the knowledge score and the socio-demographic factors.

\section{Parents' preference of dosage forms}

Figure 2 provides the parents' most preferable medicines dosage forms and shows that syrup is the most preferable (76.6\%), followed by suppositories (52.4\%), because they believe that these dosage forms can work better on their children.
Parents' attitude and beliefs regarding the efficacy and safety of self-therapy

As shown in Table 5, attitudes toward self-medication were evaluated using five questions. The first question measured positive attitude, while the last four questions measured negative attitude. Around two third of parents (77.2\%) used dietary supplements for their children, and $22.8 \%$ wrongly believed that using dietary supplements is not important for their children. 213 parents believed that, for all pills, when split in half, they provide precisely half of the therapeutic dose. 
Table 4. Parents' Knowledge towards medications used for self-therapy

\begin{tabular}{|l|c|c|c|}
\hline \multicolumn{1}{|c|}{ Items } & Yes (\%) & No (\%) & I don't know (\%) \\
\hline $\begin{array}{l}\text { Strict compliance to medication and } \\
\text { completing the medication course is } \\
\text { essential for full improvement }\end{array}$ & $\mathbf{4 7 4}(\mathbf{9 4 . 8 )}$ & $24(4.8)$ & $2(0.4)$ \\
\hline $\begin{array}{l}\text { Medicine containing more than one active } \\
\text { ingredient is more effective than medicine } \\
\text { containing one active ingredient }\end{array}$ & $181(36.2)$ & $\mathbf{1 1 5}(\mathbf{2 3 )}$ & $204(40.8)$ \\
\hline $\begin{array}{l}\text { The concentration of the active ingredient in } \\
\text { the medication depends on the child's age }\end{array}$ & $\mathbf{4 3 5 ( 8 7 )}$ & $25(5)$ & $40(8)$ \\
\hline $\begin{array}{l}\text { The greater the number of medicines used in } \\
\text { treatment, the more successful and } \\
\text { efficacious the treatment }\end{array}$ & $95(19)$ & $\mathbf{3 8 1}(\mathbf{7 6 . 2})$ & $24(4.8)$ \\
\hline $\begin{array}{l}\text { Frequent use of a medication by a child for a } \\
\text { long period may harm the child's health and } \\
\text { cause side effects }\end{array}$ & $\mathbf{4 4 3 ( 8 8 . 6 )}$ & $47(9.4)$ & $10(2)$ \\
\hline $\begin{array}{l}\text { Aspirin can normally be used as self- } \\
\text { medication for children younger than } 18\end{array}$ & $39(7.8)$ & $\mathbf{3 4 1}(\mathbf{6 8 . 2 )}$ & $120(24)$ \\
\hline
\end{tabular}

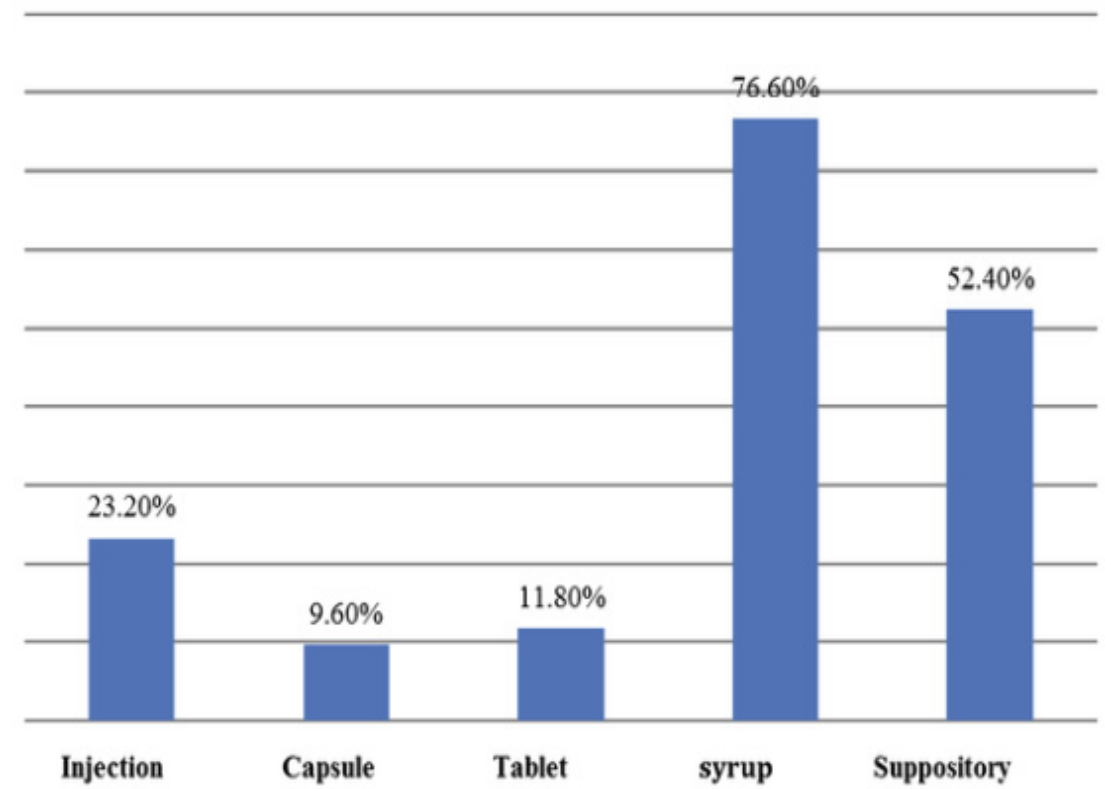

Figure 2. Dosage form preference

Table 5. Parents' attitudes and beliefs regarding self-therapy efficacy and safety

\begin{tabular}{|l|c|c|c|}
\hline \multicolumn{1}{|c|}{ Items } & Appropriately & Agree (\%) & Disagree (\%) \\
\hline $\begin{array}{l}\text { Use of dietary supplements is important for } \\
\text { children }\end{array}$ & Appropriate & $386(77.2)$ & $114(22.8)$ \\
\hline $\begin{array}{l}\text { Medicine chosen for a child without the } \\
\text { advice of a doctor or pharmacist is effective } \\
\text { and safe for the child }\end{array}$ & In appropriate & $259(51.8)$ & 241 (48.2) \\
\hline $\begin{array}{l}\text { More expensive medicine is more efficient } \\
\text { and better than less expensive medicine }\end{array}$ & In appropriate & $120(24)$ & $380(76)$ \\
\hline $\begin{array}{l}\text { When a child has suffered from a disease in } \\
\text { the past, it is correct to reuse the medicine if } \\
\text { the same symptoms arise again without the } \\
\text { advice of a doctor or pharmacist }\end{array}$ & In appropriate & $149(29.8)$ & $351(70.2)$ \\
\hline $\begin{array}{l}\text { Splitting a pill in half will give exactly half } \\
\text { of the therapeutic dose }\end{array}$ & In appropriate & $213(42.6)$ & $287(57.4)$ \\
\hline
\end{tabular}

Parents'practices regarding proper use of self-medication Approximately all parents reported providing medication to children at home. As shown in Table 6, the most commonly used medications are antipyretics $(95 \%)$, followed by skin creams (46\%) and anti-cough and anti-influenza medication $(44.2 \%)$. Only $12.2 \%$ of parents used anti-emetic as selfmedication to treat their children. More than half of parents $(53.4 \%)$ said they often record the time when giving 
Table 6. The most common medicine used by parents for their children as self-therapy

\begin{tabular}{|l|c|}
\hline \multicolumn{1}{|c|}{ Drug category } & N (\%) \\
\hline Antipyretics & $475(95)$ \\
Antibiotics & $196(39.2)$ \\
Anti-diarrhoea & $119(23.8)$ \\
laxatives & $75(15)$ \\
Antiemetic & $61(12.2)$ \\
Anti-coughs & $221(44.2)$ \\
Anti-spasmodic & $162(32.4)$ \\
Skin creams & $230(46)$ \\
Influenza and flu medications & $221(44.2)$ \\
\hline
\end{tabular}

medicines to their children. Although more than two third of parents $(86.8 \%)$ generally showed good practice, some showed bad adherence to the accurate number of doses and treatments time. Only seven parents $(1.4 \%)$ do not consult the doctor or pharmacists when the symptoms of disease persist in their children. Most parents $(93.8 \%)$ indicated that they used the measurement tool available in the medicine packet. Furthermore, most parents $(95.8 \%)$ reported that they kept the medication in specific place, out of reach of their children. When we asked parents what they do with the medicine remaining at the end of treatment periods, the majority said that they got rid of it, and only seven (1.4\%) give it to someone else. Only around half of the parents $(54.6 \%)$ know the exact quantity of the measuring tool teaspoonful as being five $\mathrm{ml}$. Table 7 illustrates parents' practices regarding self-medication.

Table 7. Parents practice regarding proper use of self-medication

\begin{tabular}{|l|c|}
\hline \multicolumn{1}{|c|}{ Items } & N (\%) \\
\hline Record the time when giving the medicine for the child & $267(53.4)$ \\
\hline $\begin{array}{l}\text { Use the correct number of doses and treatment time when giving } \\
\text { medicine for the child }\end{array}$ & $434(86.8)$ \\
\hline Consult a doctor or pharmacist when the child's symptoms persist & $493(98.6)$ \\
\hline Use the measurement tool available in the packet to measure the dose & $469(93.8)$ \\
\hline Parents keep self- medications in an appropriate safe place & $479(95.8)$ \\
\hline $\begin{array}{l}\text { Parents practice towards leftover self-medication when having } \\
\text { finished using them for their child }\end{array}$ & \\
keep it to use later & $244(44.8)$ \\
Get rid of it & $419(83.8)$ \\
Give it to someone else & $7(1.4)$ \\
\hline The volume delivered by the measuring teaspoonful & \\
$3 \mathrm{ml}$ & $217(43.4)$ \\
$5 \mathrm{ml}$ & $273(54.6)$ \\
$10 \mathrm{ml}$ & $10(2)$ \\
\hline
\end{tabular}

\section{Parents' beliefs regarding toxicity of self-medication}

When parents were asked about their beliefs regarding "the side effects reported on the drug label or leaflet and how often they occurred", $85 \%$ of them thought that they only happen in some people. More details about parents' beliefs regarding the toxicity of self-medication are presented in Table 8.

Of the self-medications believed to be potentially lethal in overdose, many were unrecognised by the parents: Paracetamol (67.4\%), ibuprofen $(44.6 \%)$, multivitamins
(70\%), antihistamine (29.2\%), anti-cough (44.4\%), and antibiotics (39.6\%); (See Table 8).

\section{Discussion}

This study aimed to investigate parents' awareness about self-therapy for their children, as well as their method of using self-therapy on their children. The majority of studies on self-therapy in children have investigated the use of medicine by children themselves [17, 25, 29]. However, few surveys have measured parental knowledge,

Table 8 Parents beliefs towards toxicity of self-medication

\begin{tabular}{|l|c|}
\hline Items & Yes (\%) \\
\hline The occurrence of side effects of medicines used for children & $37(7.4)$ \\
Occurs in all persons & $425(85)$ \\
Occurs in some persons & $60(12)$ \\
Only occurs in high doses & \\
\hline Overdose of these drugs is considered fatal for a child & $163(32.6)$ \\
Paracetamol & $277(55.4)$ \\
Ibuprofen & $150(30)$ \\
Multi vitamins & $354(70.8)$ \\
Anti-histamine & $278(55.6)$ \\
Anti-cough & $302(60.4)$ \\
Antibiotic & \\
\hline
\end{tabular}


perception, and practices regarding their own selfmedication of their children $[13,15]$.

As shown in our study, parents of children with acute simple health problems, such as respiratory illnesses, cough, fever, diarrhoea, colic, and pain are likely to use self-medication for their child's treatment. We also found that the use of self-medication by parents on their children was more common if the parents had a positive attitude toward self-medication, compared with parents that had a negative attitude.

The main reasons for parents' self-medication of their children, according to our results, is that parents have experience in treating their children and are able to ascertain the nature of the disease from the child's symptoms.

In other studies, the reasons were partly different. For example, in a Vietnamese study, the reason for selfmedication was the ease of obtaining self-therapy, with no need for a doctor's prescription [17, 19]. Other Sudanese and Saudi studies have shown that people engage in selfmedication as using medical services is too expensive and time consuming $[13,14]$.

In earlier studies, experience made up a large percentage of people's sources of information about medicine [30, 31]. Similarly, we also found that the major information sources in our population were the label inside the medicine and parents previous experience. A point of interest in our result is that parents have high awareness about the importance of completing a course of treatment. However, in other studies, awareness about the importance of completing treatment for full improvement was poor [17]. This is a very important issue, especially in the case of antibiotics, because not completing the course of therapy will lead to development of medicine resistance [17].

On the question of whether "aspirin can be used as selfmedication for children younger than 18 ", this study found that around two thirds of parents have good knowledge regarding this statement, and about one third of parents were unaware in relation to this point. For example, Reye syndrome can occur as a dangerous adverse effect of aspirin in children younger than 12 [32].

Most parents thought that syrup and suppositories are better dosage forms for children. This is because syrup can be easily swallowed by a child. In addition, suppositories can result in faster temperature reductions; moreover, they are an excellent alternative for oral dosage, especially when children do not accept oral medicines. On the other hand, a previous study in Malaysia indicated that the most preferred dosage forms were injection and syrup [24].

In our study, we found that approximately two thirds of parents preferred to give their children multivitamins. A Malaysian study conducted among parents reported that $75.6 \%$ of them also give their children multivitamins [24]. Furthermore, in our study, most parents $(72.6 \%)$ tend to think that cost does not affect efficacy of treatment. This outcome is in contrast to that of Malaysian study, which found that parents tend to think that the more expensive medicines are more efficient and better than the cheapest ones [24].

Around one third of parents in our study indicated reusing kept prescription medication on their children, for cases of with the same symptoms, without the advice of a doctor or pharmacist. This finding corroborates other studies, for example, where $26.3 \%$ of Korean parents reported the same practice [27]. $46 \%$ of parents in an Indian study believed it to be correct to reuse the same medicine for the same symptoms [17]. In addition, a Yemeni study has reported similar findings [33]. In light of this data, we can infer that this practice is not correct, since similar symptoms on a second occasion may not necessarily be the result of the same disease as the first occasion.

It is an issue of great concern that around half of respondents thought that any tablet could be divided into two parts if you have to use half a tablet. Moreover, in similar study, the vast majority of respondents $(84 \%)$ have the same thought [17]. Splitting enteric coated, extended release, controlled release or other specialised dosage forms of tablets, which do not disintegrate in stomach, will lead to overdose of medicine and, in some cases, may lead to toxic effects. In addition, some medication, when broken, can irritate the stomach $[34,35]$.

Analgesics and antipyretics were the forms of medication most commonly used as self-medication for children, by 475 (95\%) parents. These results match those observed in earlier studies [13, 17, 26, 36, 37]. Furthermore, we found a high rate of antibiotics use for children among parents in our population $(39.6 \%)$. These results are consistent with data obtained in a Sudanese study, where $36.6 \%$ of parents use antibiotics for their children as self-therapy. These results are in agreement with those obtained by a Saudi study, which found $16.8 \%$ of parents using antibiotics for their children [13]. This is considered to be a significant problem, as the excessive use of antibiotics without control could lead to bacterial antibiotic resistance [38]. Addressing this problem requires suitable rules and regulations to limit the use of antibiotics.

Since parents are their children's major caregivers, they should be very careful in dealing with the right amount of medicine and the correct time to take it. In our study, the majority of parents were correct regarding the number of doses and treatment time when giving medicine for their children. Similar results were found in another study [24].

Half of the parents have good knowledge about the quantity in one teaspoonful. In contrast, an earlier study indicated that only $30 \%$ of respondents know the exact quantity in one teaspoonful [17].

The side effects of medication are problems that occur in addition to the desired therapeutic effect, and these effects 
do not occur in all people. The possible side effects and toxicities of self-medication vary with their composition. The majority of participants $(85 \%)$ have a good knowledge about the occurrence of side effects in patients.

Parents think that self-medication is safe and suitable for their children, even when giving higher amounts than recommended doses [39]. However, unfortunately, children are more vulnerable to adverse drug events than adults. For example, in our study $67.4 \%$ of respondents believed that paracetamol is safe, even in very high doses, and this misconception is very dangerous because high doses of paracetamol can lead to hepatotoxicity [40]. The same is the case with Ibuprofen and multivitamins, where a large proportion of respondents thought that a high dose of these medicines is safe for their children. Ibuprofen overdose is a serious problem because it affects the gastrointestinal tract and causes metabolic acidosis, furthermore, ibuprofen toxicity doesn't has a specific antidote [41]. As such, parents should be warned about the dangers of excessive medication consumption.

\section{Strenghts and limitations}

The main strength of this study is the use of a large and evenly selected sample from private and government clinics. Furthermore, this study focuses on parental unawareness about several medicine-use practices in children, which hasn't been discussed in earlier studies in Palestine, suggesting a serious need for interventions to raise awareness among parents. One of the limitations of our study was that the answers reported by the parents cannot be confirmed, and recall bias is probable. In addition, this study is not a representative sample because most of the participants were mothers, so these findings display the knowledge and attitude of mothers, not fathers. Another limitation is that our data was collected from only two places.

\section{Conclusion}

Self-medication use has been common among parents for their children in Palestine. The aim of this study is to form future plans to increase awareness about, and thereby decrease hazards related to, self-therapy. There has been a high tendency for parents to use self-medication on their children, especially antipyretics. Furthermore, antibiotics have been used without prescriptions by a large proportion of parents. These should be further regulated and require a parent-focused education programme in Palestine. As such, specific guidelines for appropriate self-therapy should be established. In addition, we hope that this study will be used in future to improve parents' knowledge about selftherapy, to ensure that children receive the best treatment. We must encourage the role of pharmacists in educating parents on how to use self-medicating medicine in proper doses and at the correct time, as well as regarding when doses reach toxic levels.

\section{List of abbreviations}

KAP, knowledge, attitudes, and practices; SPSS, Statistical Package for the Social Sciences; NIS, New Israeli Shekel; IRB, Institutional Review Boards

\section{Declarations}

\section{Ethics approval and consent to participate}

All aspects of the study protocol were approved by IRB at An-Najah National University. Permission to interview parents was granted by the Palestinian Ministry of Health or a head of a private clinic. Data was collected from parents only upon obtaining verbal informed consent in line with the requirements of the IRB. Furthermore, the parents were notified that their answers would be kept totally confidential and would only be used for scientific research purposes. Informed verbal consent was obtained by all the parents and approved by the IRB committee because the study imposes minimal risk on study participants, and no personal data would be noticed in any publication arising from the study.

\section{Consent for publication \\ Not applicable}

\section{Availability of data and materials}

The datasets used and/or analysed during the current study are available from the corresponding author on reasonable request.

\section{Competing interests}

The authors declare that they have no competing interests.

\section{Funding}

No funding was received in the preparation of this study.

\section{Authors' contributions}

$\mathrm{RS}, \mathrm{DH}, \mathrm{SS}, \mathrm{HK}$, and RZ conducted the data collection, performed the analyses and literature search, and drafted the manuscript. SZ conceived the research idea, designed the study, led the data analysis and interpreted the data, monitored the whole research process, and participated in drafting the manuscript. AO, WS, RA, and SA participated in the design of the study, and revised the article for important intellectual content. All authors read, and approved the final manuscript.

\section{Acknowledgements}

We greatly appreciate the Ministry of Health for their approval, and authorization in conducting this study.

\section{References}

1. Hughes CM, McElnay JC, Fleming GF: Benefits and risks of self medication. Drug Saf 2001, 24(14):1027-1037.

2. Ruiz ME: Risks of self-medication practices. Curr Drug Saf 2010, 5(4):315-323.

3. Pereira FS, Bucaretchi F, Stephan C, Cordeiro R: Self-medication in children and adolescents. $J$ Pediatr (Rio J) 2007, 83(5):453-458.

4. Aoyama I, Koyama S, Hibino H: Self-medication behaviors among Japanese consumers: sex, age, and SES differences and caregivers' attitudes toward their children's health management. 
Asia Pac Fam Med 2012, 11(1):7.

5. Lee D, Balasubramaniam K, Ali H: Drug utilization studies: Their transferability between industrialized and developing countries. WHO Reg Publ Eur Ser 1993, 45:193-193.

6. Fosarelli P, Wilson M, DeAngelis C: Prescription medications in infancy and early childhood. Am J Dis Child 1987, 141(7):772-775.

7. Kai J: Parents and their child's fever: do as I say, not as I do? Fam Pract 1998, 15(6):505-506.

8. Kogan MD, Pappas G, Stella MY, Kotelchuck M: Over-the-counter medication use among US preschool-age children. JAMA 1994, 272(13):1025-1030.

9. Narui K, Suetsugu D, Watanabe K: Survey of Consumer Views on Non-prescription Drugs and Self-medication before Enactment of Revised Pharmaceutical Affairs Law in 2009. Japanese $J$ Pharm Health Care Sci 2010, 36(4):240-251.

10. Eiland LS, Salazar ML, English TM: Caregivers' perspectives when evaluating nonprescription medication utilization in children Clin Pediatr (Phila) 2008, 47(6):578-587.

11. Forward SP, Brown TL, McGrath PJ: Mothers' attitudes and behavior toward medicating children's pain. Pain 1996, 67(23):469-474

12. Rony RY, Fortier MA, Chorney JM, Perret D, Kain ZN: Parental postoperative pain management: attitudes, assessment, and management. Pediatrics 2010, 125(6):e1372-1378.

13. Eldalo AS: Saudi parent's attitude and practice about selfmedicating their children. Arch Pharma Pract 2013, 4(2):57-62.

14. Eldalo AS, El-Hadiyah TM, Yousif M: Sudanese parents' knowledge, attitudes and practice about self-medication to their children: Qualitative study. Saudi J Health Sci 2013, 2(2):103.

15. Tibdewal S, Gupta M: Mother's use of medication in their children of preschool age. Indian J Public Health 2005, 49(1):27-29.

16. Jemaa FC, Khaldi A, Bessioud L, Borhene J, Akkad T, Ltaief G: 1304 Self Medication in Children at the District of Tunis (Tunisia): Focus on Antibiotic Self Medication. Pediatr Res 2010, 68:645645 .

17. Sontakke S, Magdum A, Jaiswal K, Bajait C, Pimpalkhute S: Evaluation of parental perception about self-medication and other medicine use practices in children. European J Pharm Med Res 2015, 2(7):179-185.

18. Siponen S, Ahonen R, Kiviniemi V, Hämeen-Anttila K: Association between parental attitudes and self-medication of their children. International journal of clinical pharmacy 2013, 35(1):113-120.

19. Le TH, Ottosson E, Nguyen TK, Kim BG, Allebeck P: Drug use and self-medication among children with respiratory illness or diarrhea in a rural district in Vietnam: a qualitative study. $J$ Multidiscip Healthc 2011, 4:329-336.

20. Zyoud SH, Abu Taha A, Araj KF, Abahri IA, Sawalha AF, Sweileh WM, Awang R, Al-Jabi SW: Parental knowledge, attitudes and practices regarding antibiotic use for acute upper respiratory tract infections in children: a cross-sectional study in Palestine. BMC Pediatr 2015, 15:176.

21. Zyoud SH, Al-Jabi SW, Sweileh WM, Nabulsi MM, Tubaila MF, Awang R, Sawalha AF: Beliefs and practices regarding childhood fever among parents: a cross-sectional study from Palestine. BMC Pediatr 2013, 13:66.

22. Zyoud SH, Al-Jabi SW, Nabulsi MM, Tubaila MF, Sweileh WM, Awang R, Walsh A: The Validity and Reliability of the Parent Fever Management Scale: A Study from Palestine. Matern Child Health J 2015, 19(8):1890-1897.

23. Albsoul-Younes A, Tahaineh L, Moumani B: Parents' knowledge, perception, and practices of over-the-counter medicines used for their children. Jordan J Pharm Sci 2012, 4(3):181-189.

24. Dawood OT, Ibrahim MI, Palaian S: Parent's knowledge and management of their children's ailments in Malaysia. Pharm Pract (Granada) 2010, 8(2):96-102.

25. Du Y, Knopf H: Self-medication among children and adolescents in Germany: results of the National Health Survey for Children and Adolescents (KiGGS). Br J Clin Pharmacol 2009, 68(4):599608.

26. Garofalo L, Di Giuseppe G, Angelillo IF: Self-medication practices among parents in Italy. Biomed Res Int 2015, 2015:580650.

27. You MA, Nam SM, Son YJ: Parental Experiences of Medication Administration to Children at Home and Understanding of Adverse Drug Events. J Nurs Res 2015, 23(3):189-196.

28. Huott MA, Storrow AB: A Survey of Adolescents' Knowledge Regarding Toxicity of Over-the-counter Medications. Acad Emerg Med 1997, 4(3):214-218.

29. Buck ML: Self-medication by adolescents. $J$ Pediatr Pharm 2007 , 13(5): $1-4$

30. Gray NJ, Boardman HF, Symonds BS: Information sources used by parents buying non-prescription medicines in pharmacies for preschool children. Int J Clin Pharm 2011, 33(5):842-848.

31. Gore P, Madhavan S: Credibility of the sources of information for non-prescription medicines. J Soc Adm Pharm 1993, 10(3):109122.

32. Costello I, Wong IC, Nunn AJ: A literature review to identify interventions to improve the use of medicines in children. Child Care Health Dev 2004, 30(6):647-665.

33. Mohanna M: Self-medication with Antibiotic in Children in Sana'a City, Yemen. Oman Med J 2010, 25(1):41-43.

34. Green G, Berg C, Polli J, Barends D: Pharmacopeial standards for the subdivision characteristics of scored tablets. In: Pharmacopeial Forum: 2009; 2009: 1598-1603.

35. Quinzler R, Gasse C, Schneider A, Kaufmann-Kolle P, Szecsenyi J, Haefeli WE: The frequency of inappropriate tablet splitting in primary care. Eur J Clin Pharmacol 2006, 62(12):1065-1073.

36. Al-Ramahi R: Patterns and attitudes of self-medication practices and possible role of community pharmacists in Palestine. Int $J$ Clin Pharmacol Ther 2013, 51(7):562-567.

37. Eticha T, Mesfin K: Self-medication practices in Mekelle, Ethiopia. PLoS One 2014, 9(5):e97464.

38. Ventola CL: The antibiotic resistance crisis: part 1: causes and threats. $P$ T 2015, 40(4):277-283.

39. NamGoong B-R, Sohn H-S, Choi K-E, Shin H-T: Retrospective Drug Utilization Review on the Same-Day Multiple Prescriptions for Pediatric Outpatients. Korean J Clin Pharm 2012, 22(1):73-80.

40. Rivera-Penera T, Gugig R, Davis J, McDiarmid S, Vargas J, Rosenthal P, Berquist W, Heyman MB, Ament ME: Outcome of acetaminophen overdose in pediatric patients and factors contributing to hepatotoxicity. J Pediatr 1997, 130(2):300-304.

41. Schwaiger J, Ferling H, Mallow U, Wintermayr H, Negele RD: Toxic effects of the non-steroidal anti-inflammatory drug diclofenac. Part I: histopathological alterations and bioaccumulation in rainbow trout. Aquat Toxicol 2004, 68(2):141-150. 